\title{
Symptom Experience, Management, and Outcomes According to Race and Social Determinants Including Genomics, Epigenomics, and Metabolomics (SEMOARS + GEM): an Explanatory Model for Breast Cancer Treatment Disparity
}

\author{
Maura K. McCall ${ }^{1} \cdot$ Mary Connolly $^{1} \cdot$ Bethany Nugent $^{1} \cdot$ Yvette P. Conley $^{1} \cdot$ Catherine M. Bender $^{1}$. \\ Margaret Q. Rosenzweig ${ }^{1}$ (D)
}

Published online: 8 August 2019

(C) The Author(s) 2019

\begin{abstract}
Even after controlling for stage, comorbidity, age, and insurance status, black women with breast cancer (BC) in the USA have the lowest 5-year survival as compared with all other races for stage-matched disease. One potential cause of this survival difference is the disparity in cancer treatment, evident in many population clinical trials. Specifically, during BC chemotherapy, black women receive less relative dose intensity with more dose reductions and early chemotherapy cessation compared with white women. Symptom incidence, cancer-related distress, and ineffective communication, including the disparity in patientcenteredness of care surrounding patient symptom reporting and clinician assessment, are important factors contributing to racial disparity in dose reduction and early therapy termination. We present an evidence-based overview and an explanatory model for racial disparity in the symptom experience during BC chemotherapy that may lead to a reduction in dose intensity and a subsequent disparity in outcomes. This explanatory model, the Symptom Experience, Management, Outcomes and Adherence according to Race and Social determinants + Genomics Epigenomics and Metabolomics (SEMOARS + GEM), considers essential factors such as social determinants of health, clinician communication, symptoms and symptom management, genomics, epigenomics, and pharmacologic metabolism as contributory factors.
\end{abstract}

Keywords Breast cancer - Symptom - Social determinants · Treatment disparity $\cdot$ Chemotherapy $\cdot$ African-American $\cdot$ Dose intensity

\section{Introduction}

Breast cancer $(\mathrm{BC})$ incidence is similar among black and white women [1], except for younger black women aged 45 and under, who have higher incidence rates [2]. Yet black women die from $\mathrm{BC}$ at a rate $42 \%$ higher than white women $[1,3]$ and are more frequently diagnosed at later disease stages and with aggressive triple-negative (estrogen, progesterone, HER2/neu) tumors [2]. This increase is particularly true in BC, confirmed when a meta-analysis reported a 1.22 odds ratio for a negative effect of African-American ethnicity on BC mortality [4]. These negative outcome differences persist after controlling for disease stage and tumor type, comorbidities, age, and insurance status, which leaves the underlying cause of this disparity unexplained $[5,6]$. Receiving $\leq 85 \%$ of prescribed BC chemotherapy is associated with poor outcomes [7-9]. Racial
Margaret Q. Rosenzweig

mros@pitt.edu

Maura K. McCall

mccallm@pitt.edu

Mary Connolly

mcc55@pitt.edu

Bethany Nugent

bethany.nugent@pitt.edu
Yvette P. Conley

yconley@pitt.edu

Catherine M. Bender

cbe100@pitt.edu

University of Pittsburgh School of Nursing, 3500 Victoria Street, Pittsburgh, PA 15261, USA 
disparity in cancer treatment is documented [10] and is a potential source of the racial variance in survival rates [3, 11-17].

Suboptimal adherence to chemotherapy treatment is a multifactorial problem, which involves much more than the patient herself. The International Society for Pharmacoeconomics and Outcomes Research defines medication compliance/ adherence as "the degree or extent of conformity (most appropriately a percentage) to the recommendations about day-today treatment by the provider with respect to the timing, dosage, and frequency" [18]. Most often, studies investigating cancer treatment adherence focused on oral cancer treatments and have not included factors other than the patient's role in adherence. The term "adherence" or "compliance" carries some traditionally pejorative connotations, implying that the choice to receive less than full-dose treatment is always patient initiated. In BC treatment, the choices regarding less than full adherence to prescribed $\mathrm{BC}$ intravenous chemotherapy are most often initiated by the clinical staff rather than the patient. Treatment decisions such as capping chemotherapy dosing at a body surface area (BSA) of $2.0[19,20]$ instead of treating to full body weight or the clinician's subjective treatment decisions based on the categorization of certain women as "poor chemotherapy candidates" allowed a differential treatment approach that was potentially racially biased [21]. The standardization of chemotherapy dosing according to BSA without any or minimal cap for overweight and obese patients [22] and the standard use of national treatment guidelines in medical oncology [23] may now more closely regulate the clinician's discretion during initial treatment prescription, limiting the clinician's autonomy in prescribing nonstandard therapy or first cycle reduction. Perhaps these changes are reflected in recent studies, including our own, reporting on racial disparity in the initiation of chemotherapy. Slight to no racial disparity was found in the clinician's prescription or the patient's initiation of prescribed chemotherapy [24], but racial disparity in receiving full-dose, timely treatment across the chemotherapy continuum was noted [25-31].

The Symptom Experience, Management and Outcomes According to Race and Social determinants (SEMOARS) model was developed to address factors associated with the disparate receipt of chemotherapy. In this model, the exploration of these adjuvant $\mathrm{BC}$ chemotherapy receipt variables stresses the importance of the person within a social and environmental context.

\section{The SEMOARS + GEM Model}

The development of the SEMOARS model, with the addition of Genomics, Epigenomics, and Metabolomics (GEM) (Fig. 1), enables rasearchers to examine the variables contributing to the hypothesized explanatory model [32-41]. The
SEMOARS + GEM model identifies crucial factors that contribute to racial disparity in dose reduction and early chemotherapy termination. These factors include symptom phenotype and intensity, symptom reporting and management, and social determinants of health. In addition, the biologic variables of genomics, epigenomics during BC chemotherapy, and chemotherapy metabolism are modeled. The purpose of this paper is to provide a presentation and explanation of this model with relevant science. We will explore each variable in the model (Fig. 1) and provide current supporting evidence (Table 1).

Social Determinants of Health The model begins with the patient (within the context of her social and physical environment) initiating $\mathrm{BC}$ chemotherapy. Social determinants of health associated with increased symptom experience and intensity are considered integral and specific to each patient. Race/ethnicity, age, income, education, zip code, allostatic load, comorbidity, and self-efficacy/belief in prescribed medication are social determinants of health that may be associated with increased symptoms resulting in dose reductions, chemotherapy holds, and early therapy cessation [68-74]. The following sections provide a review of evidence of these associations to date.

Race/Ethnicity Racial and ethnic differences in treatment delivery and symptoms are documented [75-77]. Black women experience more chemotherapy delays compared with white women [47, 78]. Symptoms may be a causative factor. For example, minority women describe more symptom intensity and distress $\mathrm{BC}$ treatment $[79,80]$. In a recently completed study of 140 black women receiving adjuvant BC chemotherapy, nearly all (99\%) black women initiated chemotherapy, and almost $40 \%$ received a reduction in dose intensity, early cessation, or delay associated with symptoms and cancerrelated distress [32].

Age Evidence regarding the influence of age on symptom distress is contradictory. Older women are more likely to receive a lower chemotherapy dose intensity, due to fewer prescriptions and more dose reductions than younger women, with a subsequent decrease in overall survival [8, 42, 43]. Most studies adjust for age in their analyses, and when examined as a factor related to symptoms, age produced mixed results. Older age was associated with increased long-term peripheral neuropathy in docetaxel regimens [50] and more overall toxicity, such as chemotherapy-induced bone marrow toxicities [81]. Conversely, younger women experience an increase in symptoms related to cognitive function [82]. Miaskowski et al. examined factors across multiple tumor types associated with increased symptom distress during cancer chemotherapy and found younger age, female sex, low social support, and socioeconomic status to be characteristic 
Fig. 1 The SEMOARS + GEM explanatory model

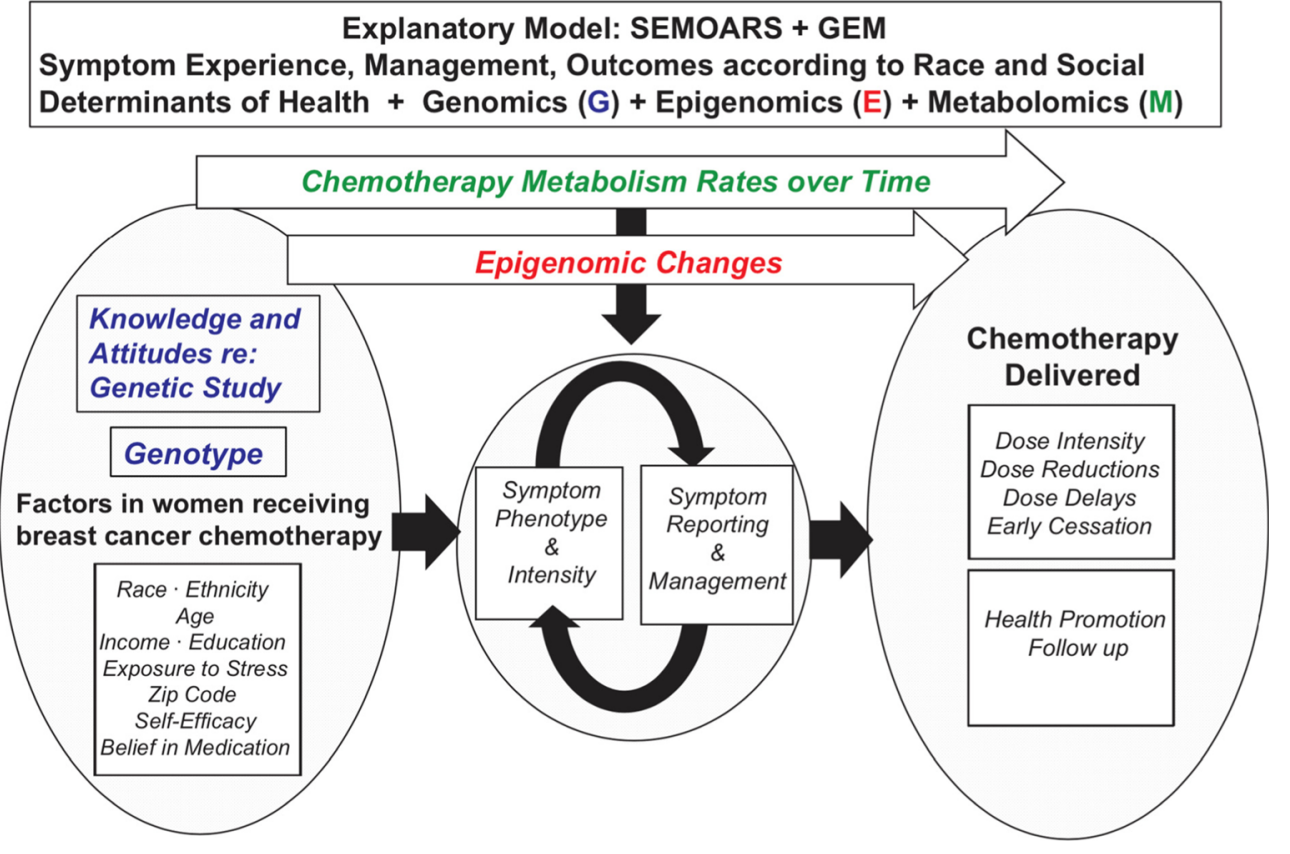

of the symptom grouping for greater symptom severity, suggesting multiple factors, including age, are related to symptoms experienced [54].

Income/Education/Zip Code Indicators of socioeconomic status, including income, education level, and zip code, affect women's experience of BC chemotherapy and overall treatment. Lower-income women are more likely to report symptoms after treatment [34] as well as a financial burden, and black women report a greater financial burden than white women after controlling for socioeconomic status [44]. Education level, which is often correlated with socioeconomic status, was inversely related to chemotherapy symptoms, with better-educated women reporting a lower symptom burden [45] and being less likely to receive a chemotherapy dose reduction [22]. Additionally, black women with less education were more likely to report perceived discrimination and disparities in their care [59].

Zip code may be used as a surrogate measure of socioeconomic status, such as income, education, and employment, in addition to the geographical region. For example, Griggs et al. found that when compared with the Northeastern region of the USA, patients in the Southern region had greater odds of receiving a reduction in their chemotherapy dose [22]. Financial, educational, and geographic factors influence symptoms and BC treatment intensity.

Allostatic Load Allostatic load is an algorithmic risk factor representing cumulative stress exposure causing persistent, severe psychological and physical symptoms for any illness, specifically cancer. Geronimus et al. used the term "weathering" to characterize the effect of cumulative stress from multiple stressors on US blacks in their residential, occupational, and other environments [83]. Thus, among black and low-income women, there is increasing concern about the impact of a lifetime of accumulated stress on illness outcomes, including $\mathrm{BC}$ outcomes $[84,85]$. The impact of the full range of childhood and cumulative adult-life stress exposure has not yet been studied in relation to cancer-related symptoms.

Comorbidity Black women with $\mathrm{BC}$ have more comorbid conditions [86] than white women has implications for BC outcomes. For example, hypertension accounted for $30 \%$ of racial survival disparity for one BC cohort [56]. An 18\% increased risk of death was observed with each additional comorbid condition [57]. Comorbidities may interfere with treatment and are associated with chemotherapy delays [47, 87]. A meta-analysis concluded that patients with comorbidities had lesser odds of receiving chemotherapy and greater odds of toxicity [88]. The precise means by which comorbidities increase symptom incidence and distress and influence chemotherapy intensity is not clear.

Beliefs and Communication The belief that medication is necessary and efficacious, in addition to the concern over possible harmful effects, can influence whether a patient will carry out a prescribed treatment [58]. Concern may result from mistrust among black patients in a traditionally white health care system or belief among black women that health care providers are not sufficiently culturally sensitive to address specific concerns $[59,60,89,90]$. Communication is essential to establishing trust in the provider-patient relationship and was negatively correlated with medical mistrust among black women with BC [59]. The communication patterns between clinician 
Table 1 Influence of social determinants of health, symptom experience, genomics and epigenomics on outcomes during breast cancer chemotherapy

Age

Griggs et al. [26]

Sample $N=1403$

Black 361

Low-acculturated Hispanic 186

High-acculturated Hispanic 183

Non-Hispanic white 673

Inwald et al. [42]

Sample $N=3463$

Bavaria, Germany, no race data reported

Owusu et al. [43]

Sample $N=689$

White 643

Minorities 46

Sandy \& Della-Fiorentina [8]

Sample $N=308$

Sydney, Australia, no race data reported

\section{Income/insurance}

Griggs et al. [26]

Sample $N=1403$

Black 361

Low-acculturated Hispanic 186

High-acculturated Hispanic 183

Non-Hispanic white 673

Wells et al. [24]

Sample $N=99$

Black 51

White 48

\section{Financial toxicity}

Wheeler et al. [44]

Sample $N=2494$

Black 49\%

White $51 \%$

\section{Education and symptoms}

Prigozin et al. [45]

Sample $N=51$

\section{Race and adherence}

Griggs et al. [26]

Sample $N=1403$

Black 361

Low-acculturated Hispanic 186

High-acculturated Hispanic 183

Non-Hispanic white 673

Wells et al. [24]

Sample $N=99$

Black 51

White 48

K. Smith et al. [46]

Sample $N=121$

Black 21

White 98
Multivariable logistic regression

o Increased age had lesser odds of receiving chemotherapy: OR 0.91 (95\% CI 0.90-0.92)

Frequency

o Women $>70$ years old were treated less frequently with chemotherapy + endocrine therapy (6.9\%) than 50-69 years old women $(28.3 \%)$

Chi-square

o Women $>75$ years old (9\%) received less chemotherapy compared with 65 to $\leq 75$ years $(28 \% ; p<.0001)$

Multivariable regression with backwards selection

o Women age $\geq 65$ years old had greater odds of having a dose reduction adjusted OR 8.36; 95\% CI $2.40-29.08 ; p=.001$

Multivariable logistic regression

- Medicaid versus other insurance lesser odds of receiving chemotherapy OR 0.59; $95 \% \mathrm{CI}$, $0.37-0.95$

Logistic regression

- Medicaid/no insurance versus private/private+Medicare* related to adherence to chemotherapy: $\beta=-2.111$;

- Adjusted OR 0.121; $p=.016$

Multivariable logistic regression predicted risk for black women compared with white

- Financial barrier adjusted risk difference 13.09 (SE 1.50) $p<.001$

- Insurance loss adjusted risk difference 3.37 (SE 0.83) $p<.001$

Pearson's $r$ :

o Education and total symptom scores were inversely related $r_{\mathrm{s}}=-0.41 ; p<.01$

Multivariable logistic regression receipt of chemotherapy compared with non-Hispanic white women

- Black women (ns) OR $0.8395 \%$ CI 0.64-1.08

- Hispanic low acculturated women OR 2.00; 95\% CI 1.31-3.04

- Hispanic high acculturated women OR 1.43; 95\% CI 1.03-1.98

Chi-square

- No difference in adherence to chemotherapy between black and white patients: $\chi^{2}=2.627$, $p=.10$

Relative Risk

- Modification of chemotherapy treatment in black versus white women: $\mathrm{RR}=1.56 ; p=.04$

- Black women received reduced cumulative doses of adjuvant chemotherapy: $\mathrm{RR}=2.49 ; p=.03$ 
Table 1 (continued)

Fedewa et al. [47]

Sample $N=107,587$

White $69.75 \%$

Black $11.52 \%$

Hispanic 4.57\%

Asian $2.84 \%$

Other minorities $11.32 \%$

Check et al. [48]

Sample $N=4002$ ( $N=2740$ for 6-month timepoint) Black 316

White 2672

Hispanic 498

Asian 516

Newman et al. [4]

Sample 14 studies

$N=52,474$

Black 10,001

White 42,473

\section{Symptom/severity}

Simon et al. [49]

Sample $N=126$

Black 27.8\%

White $65.1 \%$

Yee et al. [32]

Sample $N=121$

Black $100 \%$

Bandos et al. [50]

Sample $N=1512$

Gnerlich et al. [51]

Sample $N=243,012$

Gaston-Johansson et al. [52]

Sample $N=30$

Black 100\%

Schneider et al. [53]

Sample $N=1779$

African descent 213

European descent 1566

\section{Symptoms and race/ethnicity}

Eversley et al. [34]

Sample $N=116$

White $30 \%$

Black 30\%

Latina $25 \%$

Other minorities $15 \%$

Breast cancer survivors

\section{Miaskowski et al. [54]}

Sample $N=582$
Multivariate regression results

- Greater risk of delay in black women $(6.78 \%$ versus white $3.59 \%)$ :

60-day delay $\mathrm{RR}=1.36$; 95\% CI, 1.30-1.41

90-day delay $\mathrm{RR}=1.56$; $95 \% \mathrm{CI}, 1.44-1.69$

- Greater risk of delay in Hispanic women (6.91\% versus white $3.59 \%)$ :

60-day delay $\mathrm{RR}=1.31 ; 95 \% \mathrm{CI}, 1.23-1.39$

90-day delay $\mathrm{RR}=1.41 ; 95 \% \mathrm{CI}, 1.26-1.59$

Generalized Linear Model Step-wise Regression with cancer-specific physical well-being and 1) race 2) clinical and demographics 3 ) interpersonal processes of care for black women:

- At baseline, interpersonal processes of care domains for compassion $(\beta=0.40 ; p=.02)$, elicited concerns $(\beta=0.59 ; p=.0009)$, and explained results $(\beta=0.46 ; p=.002)$ were positively associated with physical well-being and discrimination due to race was negatively associated $(\beta=-0.58 ; p=.005)$

- Black and white women differences in physical well-being widened at 6 months $(\beta=-0.99 ; p=$ .02)

Pooled meta-analysis of breast cancer mortality in black compared with white women:

- Random effects for mortality OR 1.215 ; $95 \%$ CI $1.13-1.30$

- Adjusted for socioeconomic status OR 1.27; 95\% CI 1.17-1.38

Independent sample $t$ test chemotherapy induced peripheral neuropathy (CIPN) black women experienced and reported more CIPN compared with white women:

- Sensory scale: 28.6 versus $14.4, p<.002$

- Motor scale: 25.0 versus $15.6, p<.012$

- Autonomic scale: 24.3 versus $13.4, p<.014$

- Reported CIPN: $82.9 \%$ versus $67.1 \%$

Pearson Correlation

- Full dose chemotherapy at midpoint with:

o Symptom distress at baseline $\mathrm{r}=0.243 ; p=.007$; mid-chemo course $\mathrm{r}=0.187, p=.042$; and completion $\mathrm{r}=0.180, p=.050$

o Total number of symptoms at baseline $\mathrm{r}=-0.225, p=.014$

- Full dose chemotherapy at endpoint with:

o Total number of symptoms at baseline $\mathrm{r}=0.189 ; p=.039$

Multivariable ordinal logistic regression

- Women $\geq 50$ were more likely to experience long term peripheral neuropathy OR $1.34 ; 95 \%$ CI $1.10-1.65 ; p=.005$

Cox regression

- Younger ( $<40$ years old) were more likely to die with Stage 1 (adjusted HR 1.44; $95 \% \mathrm{CI}$ 1.27-1.64) or Stage 2 (adjusted HR 1.09; 95\% CI 1.03-1.15) than women older than 40

Chi-square

- Symptoms increased at midpoint of chemotherapy and then decreased or remained the same at completion. For example, worst pain $\chi^{2}=7.81, p=.027$

Logistic regression with Cox hazard ratio

- Compared with other races, patients of African descent had increased risk of taxane-induced peripheral neuropathy (TIPN) grade 2-4 HR 2.1; $p=5.6 \times 10^{-16}$ and grade 3-4 HR 2.6; $p=1.1 \times 10^{-11}$

Comparing race/ethnicity:

o Latina reported more symptoms $(\mu=2.5)$ than black $(\mu=1.5)$ or white $(\mu=1.2 ; p<.01)$

o Black $(91 \%)$ and Latina $(93 \%)$ reported more pain (white $54 \% ; p<.001$ )

o Latina $(89 \%)$ reported more depressive symptoms compared with black $(38 \%)$ and white $(40 \% ; p<.001)$

Least Squares Regression for total number of symptoms:

o Income $\beta=-0.397 p=.003$

o Mastectomy $\beta=0.340 p=.005$

o Chemotherapy $\beta=0.340 p=.026$

o Latina $\beta=0.340 p=.004$

Latent Class Analysis yielded 3 trajectories for symptoms:

o "All High" $13.9 \%$ of patients 
Table 1 (continued)

Breast, gastrointestinal, gynecological, or lung cancer o Younger age $\mathrm{F}=6.07 ; p=.002$ (low versus moderate and high)

patients undergoing chemotherapy

o Less education $\mathrm{F}=5.00 ; p=.007$ (low versus moderate and high)

o Minorities $\chi^{2}=8.81 ; p=.012$ (low versus moderate and high)

o Lower income $\mathrm{KW}=22.81 ; p<.0001$ (low and moderate versus high)

o Breast cancer $\chi^{2}=11.17 ; p=.083$

o More comorbidities $\mathrm{F}=38.99 ; p<.0001$ (low versus moderate versus high)

o Lower reported functional status $\mathrm{F}=38.73 ; p<.0001$ (low versus moderate versus high)

o "Moderate" $50 \%$ of patients

o "Low" $36.1 \%$ of patients

o Fewer females $\chi^{2}=24.39 ; p<.0001$ (low versus moderate and high)

o More married/partnered $\chi^{2}=10.80 ; p=.005$ (low versus high)

\author{
Comorbidities and cancer \\ Leach et al. [55] \\ Sample $N=1527$ \\ Black $18.1 \%$ \\ White $50.5 \%$ \\ Other minorities $31.4 \%$
}

\author{
Comorbidity and adherence \\ Fedewa et al. [47] \\ Sample $N=107,587$ \\ Black $11.52 \%$ \\ Hispanic $4.57 \%$ \\ Asian $2.84 \%$ \\ White $69.75 \%$ \\ Other minorities $11.32 \%$
}

\section{Comorbidity and survival}

Braithwaite et al. [56]

Sample $N=1254$

Black 416

White 838

\author{
Klepin et al. [57] \\ Sample $N=329$ \\ Black $11 \%$ \\ White $87 \%$ \\ Other minorities $1 \%$ \\ Unknown $1 \%$
}

\section{Beliefs and adherence}

Gatti et al. [58]

Sample $N=275$

Black $86.2 \%$

White $5.1 \%$

Other minorities $8.7 \%$

\section{Spirituality and patient-reported outcomes}

Gaston-Johansson et al. [52]

Sample $N=30$

Black $100 \%$

\section{Interpersonal communication and mistrust}

Sutton et al. [59]

Sample $N=210$

Black $100 \%$

Tucker et al. [60]

Sample $N=298$

Black $100 \%$
Prevalence and Linear Regression:

o Compared with breast cancer survivors, fewer comorbidities were reported by prostate cancer survivors $\beta=-1.22 ; p=.0001$; as well as colorectal cancer survivors $\beta=-0.62$; $p=.0243$ and ovarian cancer survivors $\beta=-0.55 ; p=.042$

o Compared with white cancer survivors, black cancer survivors reported fewer comorbidities $\beta=-0.89 ; p=.0112$

o Breast cancer survivors reported having experienced more comorbidities (5.8; 95\% CI $5.4-$ 6.2) than survivors of other cancers

Multivariate regression results

Greater risk of delay compared with no comorbidity:

- 60-day delay 1 comorbidity RR=1.09; 95\% CI, 1.04-1.14

$\geq 2$ comorbidities $\mathrm{RR}=1.32 ; 95 \% \mathrm{CI}, 1.21-1.45$

- 90-day delay 1 comorbidity $\mathrm{RR}=1.13 ; 95 \% \mathrm{CI}, 1.34-1.23$

$\geq 2$ comorbidities $\mathrm{RR}=1.32 ; 95 \% \mathrm{CI}, 1.10-1.60$

Logistic regression with Cox hazard ratios

- Hypertension increased risk of mortality after adjusting for age and race HR 1.33 95\% CI $1.07-1.67$

Multivariable logistic regression for overall survival

- Total number of comorbidities HR $1.18 ; 95 \%$ CI 1.06-1.33; $p<.01$

Multivariable logistic regression on medication adherence in general

- Negative beliefs about medication is a predictor of low adherence adjusted OR 2.12;95\% CI $1.3-3.7 ; p=.006$

Correlation

- Negative religious coping correlated with psychological distress $\mathrm{r}=0.6 ; p<.05$, anxiety $\mathrm{r}=$ $0.51 ; p<.05$, and depression $\mathrm{r}=0.65 ; p<.01$

Multiple linear regression

- Low rating of chemotherapy communication was associated with greater medical mistrust high school or less $p=.02$

Mediation analysis

- Trust mediated the role of cultural sensitivity in the domains of provider competence/ confidence, provider sensitivity/interpersonal skill, and provider respect/communication with patient satisfaction 
Table 1 (continued)

\begin{tabular}{|c|c|}
\hline $\begin{array}{l}\text { Jiang et al. [33] } \\
\text { Sample } N=101 \\
\text { Black } 100 \%\end{array}$ & $\begin{array}{l}\text { Multiple linear regression } \\
\text { - Perceived better physician interpersonal communication was positively associated with } \\
\text { beliefs in the necessity of chemotherapy } \beta=0.057 ; p=.007\end{array}$ \\
\hline \multicolumn{2}{|c|}{ Genomics and taxane-induced peripheral neuropathy (TIPN) } \\
\hline $\begin{array}{l}\text { Schneider et al. [61] } \\
\text { Sample } N=213 \\
\text { Black } 100 \%\end{array}$ & $\begin{array}{l}\text { Gene-based case control statistical analysis (SKAT) } \\
\text { - SET binding factor } 2(S B F 2) \text { was associated with TIPN } p=4.35 \times 10^{-6}\end{array}$ \\
\hline $\begin{array}{l}\text { Hertz et al. [62] } \\
\text { Sample } N=411 \\
\text { White discovery cohort } 209 \\
\text { Black replication cohort } 107\end{array}$ & $\begin{array}{l}\text { Log-rank test and Cox proportional hazards } \\
\text { - In European-American discovery cohort, } C Y P 2 C 8 * 3 \text { genotype increased risk of grade } 2+ \\
\text { neuropathy for each allele HR }=1.95 ; 95 \% \text { CI } 1.06-3.58 ; p=.031 \\
\text { - In African-American replication cohort, no homozygotes were found, but one allele of } \\
\quad C Y P 2 C 8 * 3 \text { increase TIPN risk HR }=3.30 ; 95 \% \text { CI } 1.04-10.45 ; p=.043\end{array}$ \\
\hline $\begin{array}{l}\text { Baldwin et al. [63] } \\
\text { Sample } N=1126 \\
\text { White discovery cohort } 855 \\
\text { Black replication cohort } 154 \\
\text { White replication cohort } 117\end{array}$ & $\begin{array}{l}\text { Ordinal logistic regression } \\
\text { o In the white (European) discovery cohort, FGD4 was associated with TIPN HR } 1.57 ; 95 \% \\
\text { CI } 1.30-1.91 ; p=2.6 \times 10^{-6} \\
\text { o The white replication cohort was similar HR } 1.72 ; 95 \% \text { CI } 1.06-2.80 ; p=.013 \\
\text { o The black replication cohort was also associated HR } 1.93 ; 95 \% \text { CI } 1.13-3.28 ; p=6.7 \times 10^{-3}\end{array}$ \\
\hline $\begin{array}{l}\text { Abraham et al. [64] } \\
\text { Sample } N=1303 \text { samples from several trials } \\
\text { White } 100 \%\end{array}$ & $\begin{array}{l}\text { Unconditional logistic regression and likelihood ratio test } \\
\text { o ATP-binding cassette, subfamily } B(A B C B 1) \text { was associated with decreased odds of TIPN } \\
\text { OR } 0.47 ; 95 \% \text { CI } 0.28-0.79 ; p=.004 \\
\text { o Tubulin Beta } 2 A \text { Class IIa }(\text { TUBB2A) was also associated with increased odds of TIPN OR } \\
\quad 1.80 ; 95 \% \text { CI } 1.20-2.72 ; p=.005\end{array}$ \\
\hline $\begin{array}{l}\text { Apellaniz-Ruiz et al. [65] } \\
\text { Sample } N=146 \\
\text { White } 100 \%\end{array}$ & $\begin{array}{l}\text { Cumulative dose analysis and additive model } \\
\text { o Ephrin Receptor A5 (EPHA5) was associated with TIPN HR 2.3;95\% CI 1.6-3.9; } p=.0074 \\
\text { o Ephrin Receptor A6 (EPHA6) was associated with TIPN HR 1.9;95\% CI 1.2-2.9; } p=.0063 \\
\text { o Ephrin Receptor A8 (EPHA8) was associated with TIPN HR } 1.9 ; 95 \% \text { CI } 1.1-3.2 ; p=.0012\end{array}$ \\
\hline $\begin{array}{l}\text { Boso et al. [66] } \\
\text { Sample } N=113 \\
\text { White } 100 \%\end{array}$ & $\begin{array}{l}\text { Multivariate logistic regression } \\
\text { o Excision repair cross complementation group } 1 \text { (ERCC1) was associated with TIPN } p=.006\end{array}$ \\
\hline \multicolumn{2}{|l|}{ Epigenomics and chemotherapy } \\
\hline $\begin{array}{l}\text { Smith et al. [67.] } \\
\text { Sample } N=61 \\
\text { Black } 25 \\
\text { White } 36\end{array}$ & $\begin{array}{l}\text { Linear regression (MethLAB) } \\
\text { o CpG sites with change in methylation after chemotherapy versus no chemotherapy included } \\
\text { o cg26077811 } \beta=-.074, p=3.65 \times 10^{-9} \\
\text { o } \operatorname{cg} 18942579 \beta=-.161, p=1.65 \times 10^{-8} \\
\text { o } \operatorname{cg} 12054453 \beta=-.154, p=2.75 \times 10^{-8} \\
\text { o } \operatorname{cg} 16936953 \beta=-.168, p=3.26 \times 10^{-8} \\
\text { o } \operatorname{cg} 05438378 \beta=-.089, p=7.78 \times 10^{-8} \\
\text { o } \operatorname{cg} 25446789 \beta=-.085, p=7.84 \times 10^{-8} \\
\text { o } \operatorname{cg} 01409343 \beta=-.138, p=9.88 \times 10^{-8} \\
\text { o } \operatorname{cg} 13518625 \beta=-.051, p=9.98 \times 10^{-8}\end{array}$ \\
\hline
\end{tabular}

Where studies categorized race as other or nonwhite (likely grouped due to the sample size), we used the terms minorities or other minorities $n s$, not significant; $O R$, odds ratio; $H R$, hazard ratio; $C I$, confidence interval; $R R$, relative risk; $S E$, standard error; $S D$, standard deviation; $\beta$, beta; $\mu$, mean; $K W$, Kruskal-Wallis; $\chi^{2}$, chi-square; $R R$, risk ratio; "white" was used in some cases when European ancestry was indicated

*Health insurance variable was a surrogate for income/socioeconomic class

**Only measured number of sessions, not dose. Adherence divided into $100 \%$ attendance or less than $100 \%$ and was defined by patient factors: missed appointments, cancellations, no shows, etc.; no delays or discontinuations by the provider were noted

and patient, described as the patient centeredness of care (PCC), coded and scored through a 23-item checklist, may be an important explanation for racial differences in communication during BC clinical visits. Rosenzweig's team described a prospective, comparative pilot study qualitatively coded for PCC during the clinical visit of women undergoing $\mathrm{BC}$ chemotherapy and compared by race. Twenty-four clinical visits were recorded in a sample of five black and five white women undergoing BC chemotherapy. Overall for each PCC item, the mean clinician visit scores for black women were higher (worse PCC) than the mean clinician visit scores for white women. Significant differences were found in $27 \%$ of the PCC items. The higher scores were evident for three of the four subscales "Invest in the Beginning," "Elicit the Patient's Perspective," and "Demonstrate Empathy" [91]. 


\section{Symptom Phenotype and Intensity}

For all women, once the chemotherapy dosing is calculated and initiated, follow-up doses may be decreased, held, or discontinued if patients exhibit symptoms of toxicity. There is a pattern during chemotherapy that symptoms increase from pre-chemotherapy to mid-therapy but stabilize after chemotherapy treatment midpoint to completion [32, 52], suggesting a symptom tolerance among patients. Associations between the ability to receive $\geq 85 \%$ of the prescribed treatment course and symptom distress, severity, and the total number of symptoms at pre-chemotherapy are reported [32]. Minority patients were more likely to belong to the high-symptom group when symptom severity was categorized into low, moderate, and high [54]. Other variables to consider in racial symptom and treatment disparity include baseline genomics and temporal epigenomic changes that may be associated with symptom phenotype and treatment response.

\section{Genomics and Epigenomics of Symptoms and Chemotherapy Metabolomics}

Though social determinants of health are factors related to disparity in dosing and completion of chemotherapy, they do not fully account for the disparity in BC symptoms and ability to receive the full dose of chemotherapy in black women compared with white women. Genomic variation may help to explain a portion of these differences. For example, taxane-based chemotherapy used in BC treatment has a highly variable drug response and symptom profile and is metabolized through the cytochrome $\mathrm{P} 450$ system. Variations in cytochrome $\mathrm{P} 450$ genes $C Y P 3 A 4, C Y P 3 A 5$, and $C Y P 2 C 8$, as well as transporter genes $A B C B 1, A B C B 2$, and $S C L O 1 B 3$, would likely result in individual differences in drug metabolism [92]. Genotype variations may result in an increase or decrease in patients' symptoms, based upon the drug and the gene's role in metabolism. CYP $2 C 8 * 3$ was associated with grade $2+$ neuropathy in European- and African-Americans treated with paclitaxel, but African-Americans with the variant had greater odds of developing taxane-induced peripheral neuropathy, and no homozygotes for the variant were observed [62].

There is considerable variability in absorption, distribution, metabolism, and excretion (ADME) of drugs. These differences can be explained by genetic variation in ADME-related genes [93]. ADME-related genetic variability often differs across populations [94] and helps to explain the link between ancestry and variable chemotherapy drug response [95]. Li et al. observed greater diversity in $\mathrm{ADME}$ genes for the African-American population compared with European and African populations [96], predisposing African-Americans to more variable drug response. Gene variations may alter drug metabolism by activating or inactivating a medication, activating or inactivating a drug's metabolite, affecting the medication's transport, or affecting the drug's intended target [97]. Concomitant medications may also facilitate or interfere with drug metabolism.

Genes not directly involved in drug metabolism may affect symptoms experienced among diverse ancestries. For example, taxane-induced peripheral neuropathy (TIPN) is a common symptom with known genomic associations. Variants in the Charcot-Marie-Tooth (CMT) disease gene, $S B F 2$, were predictors of TIPN in black patients [61]. Another CMT gene, $F G D 4$, was associated with paclitaxel-induced peripheral neuropathy in patients of European or African ancestry [63]. $A B C B 1$ (noted as a transporter above), ERCC1, TUBB2A, and $E P H A 5 / 6 / 8$ were associated with neuropathy in European samples [64-66]. Most genome-wide databases revealed focus exclusively on European populations, rather than African, Asian, and Latin American, which underscores the gap in genome-wide research and importance of recruitment for all ancestral populations in research [98, 99].

Genomic variation in ancestry and drug metabolism genes are not the only factors associated with the development of toxicities. Epigenetic changes, perhaps those caused by chemotherapy, other cancer treatments, or social determinants of health, may also increase symptoms (Fig. 2). DNA methylation, the addition of a methyl group to the nucleotide cytosine, is one type of epigenetic change which potentially affects gene expression by changing the gene's activity (increase or decrease). For example, an increase in inflammatory markers was found in patients with $\mathrm{BC}$ following a decrease in DNA methylation post-chemotherapy, indicating that DNA methylation mediated a relationship between chemotherapy and inflammatory biomarkers [67]. The study of epigenetic change resulting from chemotherapy and its influence on drug response and symptoms is an emerging field.

In summary, the SEMOARS + GEM explanatory model for disparity among black women with $\mathrm{BC}$ examines psychosocial, clinical, and biological factors impacting treatment delivery, symptoms, and outcomes. Testing each aspect of this model and determining the unique contribution of each component to overall $\mathrm{BC}$ treatment disparity is critically important to understanding the most relevant actionable targets for ensuring treatment equity.

\section{Discussion}

We presented evidence for the development of the SEMOARS + GEM model of disparity of BC treatment in black women. This comprehensive model, supported by previous research, describes a process that transpires during a $\mathrm{BC}$ diagnosis and treatment. Black women bring their life experiences and characteristics, in the form of social determinants of health and genomic profiles, at the time of diagnosis. These factors influence the patient's symptom experience including symptom phenotype, intensity, reporting to clinicians, and 


\title{
What is Social Epigenomics?
}
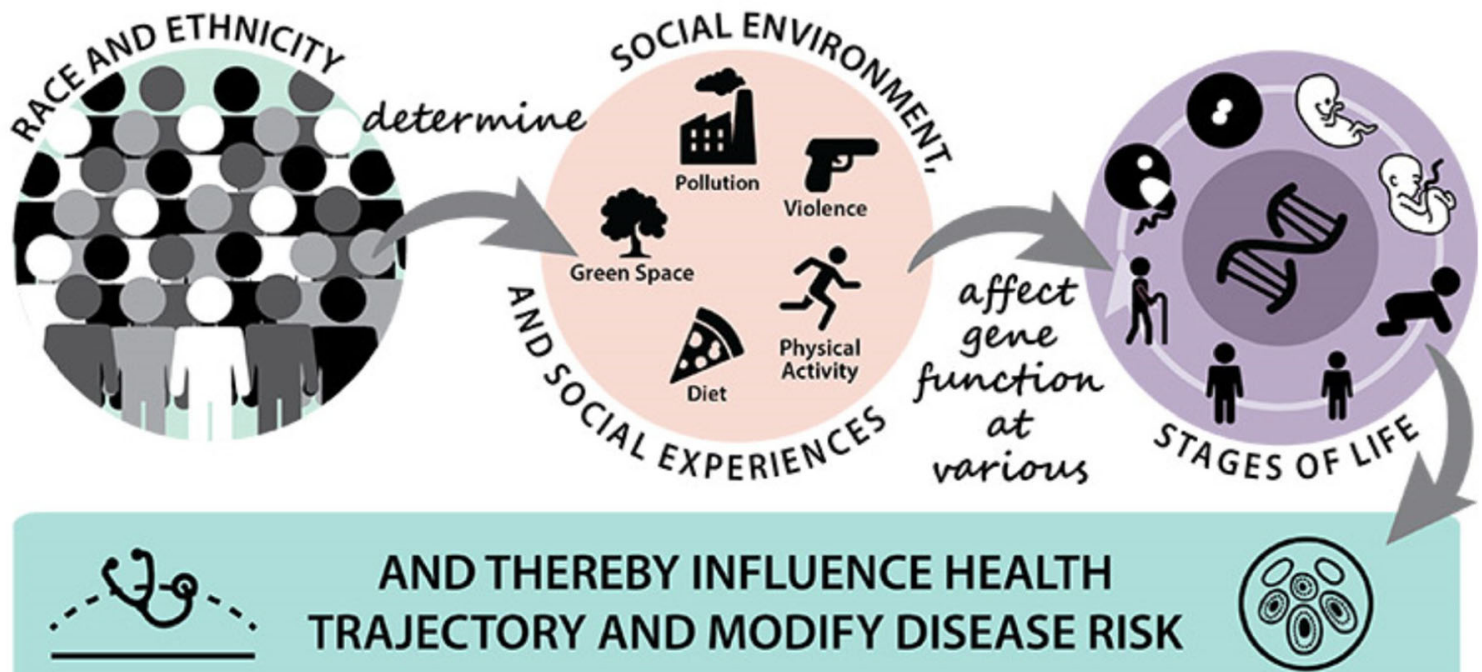

\section{THROUGH EPIGENOMIC PROFILING BEFORE THE ONSET OF DISEASES, IT MAY BE POSSIBLE TO TAILOR INTERVENTIONS TO PREVENT CHRONIC CONDITIONS OR DISEASES LATER IN LIFE}

\begin{abstract}
Figure: What is Social Epigenomics? Race and ethnicity determine social environment, and social experiences affect gene function at various stages of life, thereby influencing health trajectory and modifying disease risk. Through epigenomic profiling before the onset of diseases, it may be possible to tailor interventions to prevent chronic conditions or diseases later in life.
\end{abstract}

Fig. 2 The role of social determinants and epigenomics in health and disease. Figure used with permission from NIH (https://epi.grants.cancer.gov/ epigen.html)

subsequent clinician management. Resultant dose alterations or early cessation may occur. Epigenetic changes and chemotherapy metabolism over time may moderate the symptom experience.

Many of the variables discussed in this paper, for example, education and socioeconomic status and similarly BMI and comorbidities, are typically correlated with one another. Instead of examining race and age as predictors, many studies control for them statistically. Additionally, most study samples do not include a large enough black population to draw inferences, and few focus solely on black women.

A disparity in outcomes for black women with $\mathrm{BC}$ has been well-established, but no one factor explains the issue in its entirety. Outcomes for black women are influenced by social determinants of health [100]. Barsevick et al. reported that social determinants such as education, unemployment, marital status, age, comorbidity, and medical mistrust were factors in post-treatment burden for survivors [101]. All of these factors are examined in the SEMOARS + GEM model. Potentially pertinent factors, not examined in depth, are those addressed in the US government's public health initiative, Healthy People 2020. According to Healthy People 2020, social determinants of health encompass economic stability, education, social and community context, health and health care, and neighborhood and built environment [102]. The SEMOARS + GEM model somewhat superficially measures many of these concepts, though perhaps not as in-depth as prescribed by Healthy People 2020 .

Symptom phenotype and intensity experienced by black women are more pronounced than in white women, resulting in an inability of more black women to receive the entire chemotherapy treatment and leading to poorer outcomes. Additionally, Zannas et al. provided evidence of the impact of social determinants of health on epigenetic aging in an African-American cohort, confirming that in addition to genomics, stressors leading to physiologic changes should be further studied [103].

The SEMOARS + GEM model will add in-depth descriptive work to find actionable targets, which will inform further implementation and translation into clinical practice guidelines. Should identification of genomic associations ensue, a precision health care strategy may be routinely implemented into clinical care to identify at-risk patients for early symptom management in order to tailor chemotherapy treatments to the patient. Providing an individualized protocol for all patients with $\mathrm{BC}$, including factors specific to black women, will offer improved symptom management. Biological ancestral differences in chemotherapy metabolism and epigenomics suggest that variations influence symptom and treatment outcome differences.

The SEMOARS + GEM model includes known factors that influence a black woman's disparate BC treatment 
experience to inform future interventions to improve the ability to receive complete, effective $\mathrm{BC}$ chemotherapy.

Funding Information Funding supported by the National Institute on Minority Health and Health Disparities (1R01MD012245-01; PI: Rosenzweig) and the Center for Clinical and Translational Science, University of Pittsburgh (Feasibility and Acceptability of Genomics Research Exploring Racial Differences in Metabolism and Toxicity of Breast Cancer Chemotherapy, PI: Rosenzweig). M. McCall is also supported by National Institute of Nursing Research (T32NR009759; PI: Conley), a Doctoral Degree Scholarship in Cancer Nursing, DSCN-19049-01, from the American Cancer Society.

Open Access This article is distributed under the terms of the Creative Commons Attribution 4.0 International License (http:// creativecommons.org/licenses/by/4.0/), which permits unrestricted use, distribution, and reproduction in any medium, provided you give appropriate credit to the original author(s) and the source, provide a link to the Creative Commons license, and indicate if changes were made.

\section{References}

1. Richardson LC, Henley SJ, Miller JW, Massetti G, Thomas CC (2016) Patterns and trends in age-specific black-white differences in breast cancer incidence and mortality - United States, 19992014. MMWR Morb Mortal Wkly Rep 65:1093-1098. https:// doi.org/10.15585/mmwr.mm6540a1

2. Shoemaker ML, White MC, M W, Weir HK, Romieu I (2018) Differences in breast cancer incidence among young women aged 20-49 years by stage and tumor characteristics, age, race, and ethnicity, 2004-2013. Breast Cancer Res Treat 169:595-606. https://doi.org/10.1007/s10549-018-4699-9

3. DeSantis CE, Siegel RL, Sauer AG, Miller KD, Fedewa SA, Alcaraz KI, Jemal A (2016) Cancer statistics for African Americans, 2016: progress and opportunities in reducing racial disparities. CA Cancer J Clin 66:290-308. https://doi.org/10. $3322 /$ caac. 21340

4. Newman LA, Mason J, Cote D, Vin Y, Carolin K, Bouwman D, Colditz GA (2002) African-American ethnicity, socioeconomic status, and breast cancer survival: a meta-analysis of 14 studies involving over 10,000 African-American and 40,000 white American patients with carcinoma of the breast. Cancer 94: 2844-2854. https://doi.org/10.1002/cncr.10575

5. McCarthy AM, Yang J, Armstrong K (2015) Increasing disparities in breast cancer mortality from 1979 to 2010 for US black women aged 20 to 49 years. Am J Public Health 105:S446-S448. https:// doi.org/10.2105/AJPH.2014.302297

6. DeSantis CE, Ma J, Goding Sauer A, Newman LA, Jemal A (2017) Breast cancer statistics, 2017, racial disparity in mortality by state. CA Cancer J Clin 67(6):439-448. https://doi.org/10. $3322 /$ caac. 21412

7. Bonadonna G, Valagussa BS (1981) Dose-response effect of adjuvant chemotherapy in breast cancer. NEJM 304:10-15

8. Sandy J, Della-Fiorentina S (2013) Relative dose intensity in early stage breast cancer chemotherapy: a retrospective analysis of incidence, risk factors and outcomes at a south-west Sydney cancer clinic. Asia-Pacific J Clin Oncol 9:365-372. https://doi.org/10. 1111/ajco.12093

9. Wildiers H, Reiser M (2011) Relative dose intensity of chemotherapy and its impact on outcomes in patients with early breast cancer or aggressive lymphoma. Crit Rev Oncol Hematol 77:221-240. https://doi.org/10.1016/j.critrevonc.2010.02.002
10. Rao D, Debb S, Blitz D, Choi SW, Cella D (2008) Racial/ethnic differences in the health-related quality of life of cancer patients. J Pain Symptom Manag 36(5):488-496. https://doi.org/10.1016/j. jpainsymman.2007.11.012

11. Adams SA, Butler WM, Fulton J, Heiney SP, Williams EM, Delage AF, Khang L, Hebert JR (2011) Racial disparities in breast cancer mortality in a multiethnic cohort in the southeast. Cancer 118:2693-2699. https://doi.org/10.1002/cncr.26570

12. Bach PB, Schrag D, OW Brawley A, Galaznik SY, Begg CB (2002) Survival of blacks and whites after a cancer diagnosis. JAMA 287:2106-2113

13. Clegg LX, Li FP, Hankey BF, Chu K, Edwards BK (2002) Cancer survival among us whites and minorities: a SEER (surveillance, epidemiology, and end results) program population-based study. Arch Intern Med 162:1985-1993

14. Menashe I, Anderson WF, Jatoi I, Rosenberg PS (2009) Underlying causes of the black-white racial disparity in breast cancer mortality: a population-based analysis. J Natl Cancer Inst 101:993-1000. https://doi.org/10.1093/jnci/djp176

15. Morris AM, Rhoads KF, Stain SC, Birkmeyer JD (2010) Understanding racial disparities in cancer treatment and outcomes. J Am Coll Surg 211:105-113. https://doi.org/10.1016/j. jamcollsurg.2010.02.051

16. Penner LA, Eggly S, Griggs JJ, Underwood W, Orom H, Albrecht TL (2012) Life-threatening disparities: the treatment of Black and White cancer patients. J Soc Issues 68:328-357. https://doi.org/10. 1111/j.1540-4560.2012.01751.x

17. Shavers VL, Brown ML (2002) Racial and ethnic disparities in the receipt of cancer treatment. JNCI: J Natl Cancer Inst 94:334-357

18. Cramer JA, Roy A, Burrell A, Fairchild CJ, Fuldeore MJ, Ollendorf DA, Wong PK (2008) Medication compliance and persistence: terminology and definitions. Value Health 11:44-47. https://doi.org/10.1111/j.1524-4733.2007.00213.x

19. Gurney $\mathrm{H}$ (2002) How to calculate the dose of chemotherapy. Br J Cancer 86:1297-1302. https://doi.org/10.1038/sj/bjc/6600139

20. Gurney H (1996) Dose calculation of anticancer drugs: a review of the current practice and introduction of an alternative. J Clin Oncol 14(9):2590-2611. https://doi.org/10.1200/jco.1996.14.9.2590

21. Griggs JJ, Mangu PB, Temin S, Lyman GH, Anderson H, Balaban EP, Dignam JJ et al (2012) Appropriate chemotherapy dosing for obese adult patients with cancer: American Society of Clinical Oncology clinical practice guideline. J Oncol Pract 8:e59-e61. https://doi.org/10.1200/JOP.2012.000623

22. Griggs JJ, Culakova E, Sorbero MES, Van Ryn M, Poniewierski MS, Wolff DA, Crawford J, Dale DC, Lyman GH (2007) Effect of patient socioeconomic status and body mass index on the quality of breast cancer adjuvant chemotherapy. J Clin Oncol 25:277284. https://doi.org/10.1200/JCO.2006.08.3063

23. Smith TJ, Hillner BE (2001) Ensuring quality cancer care by the use of clinical practice guidelines and critical pathways. J Clin Oncol 19(11):2886-2897. https://doi.org/10.1200/jco.2001.19. 11.2886

24. Wells JS, Strickland OL, Dalton JA, Freeman S (2015) Adherence to intravenous chemotherapy in African American and white women with early-stage breast cancer. Cancer Nurs 38(2):89-98. https://doi.org/10.1097/NCC.0000000000000139

25. Griggs JJ, Culakova E, Sorbero ME, Poniewierski MS, Wolff DA, Crawford J, Dale DC, Lyman GH (2007) Social and racial differences in selection of breast cancer adjuvant chemotherapy regimens. J Clin Oncol 25(18):2522-2527. https://doi.org/10.1200/ JCO.2006.10.2749

26. Griggs JJ, Hawley ST, Graff JJ, Hamilton AS, Jagsi R, Janz NK, Mujahid MS et al (2012) Factors associated with receipt of breast cancer adjuvant chemotherapy in a diverse population-based sample. J Clin Oncol : official journal of the American Society of 
Clinical Oncology 30:3058-3064. https://doi.org/10.1200/JCO. 2012.41.9564

27. Hershman D, Weinberg M, Rosner Z, Alexis K, Tiersten A, Grann VR, Troxel A, Neugut AI (2003) Ethnic neutropenia and treatment delay in African American women undergoing chemotherapy for early-stage breast cancer. J Natl Cancer Inst 95:1545-1548. https://doi.org/10.1093/jnci/djg073

28. Wu XC, Lund MJ, Kimmick GG, Richardson LC, Sabatino SA, Chen VW, Fleming ST, Morris CR, Huang B, Trentham-Dietz A, Lipscomb J (2012) Influence of race, insurance, socioeconomic status, and hospital type on receipt of guideline-concordant adjuvant systemic therapy for locoregional breast cancers. J Clin Oncol 30(2):142-150. https://doi.org/10.1200/jco.2011.36.8399

29. Mandelblatt JS, Sheppard VB, Neugut AI (2013) Black-white differences in breast cancer outcomes among older Medicare beneficiaries: does systemic treatment matter? JAMA 310(4):376377. https://doi.org/10.1001/jama.2013.8273

30. Jemal A, Robbins AS, Lin CC, Flanders WD, DeSantis CE, Ward EM, Freedman RA (2018) Factors that contributed to black-white disparities in survival among nonelderly women with breast cancer between 2004 and 2013. J Clin Oncol 36:14-24. https://doi. org/10.1200/JCO.2017.73.7932

31. Silber JH, Rosenbaum PR, Clark AS, Giantonio BJ, Ross RN, Teng Y, Wang M, Niknam BA, Ludwig JM, Wang W, Even-Shoshan O, Fox KR (2013) Characteristics associated with differences in survival among black and white women with breast cancer. Jama 310(4):389-397. https://doi.org/10.1001/jama.2013.8272

32. Yee MK, Sereika SM, Bender CM, Brufsky AM, Connolly MC, Rosenzweig MQ (2017) Symptom incidence, distress, cancerrelated distress, and adherence to chemotherapy among African American women with breast cancer. Cancer 123:2061-2069. https://doi.org/10.1002/cncr.30575

33. Jiang Y, Sereika S, Bender C, Brufsky A, Rosenzweig M (2016) Beliefs in chemotherapy and knowledge of cancer and treatment among African American women with newly diagnosed breast cancer. Oncol Nurs Forum 43:180-189. https://doi.org/10.1188/ 16.ONF.180-189

34. Eversley R, Estrin D, Dibble S, Wardlaw L, Pedrosa M, FavilaPenney W (2005) Post-treatment symptoms among ethnic minority breast cancer survivors. Oncol Nurs Forum 32:250-256. https://doi.org/10.1188/05.ONF.250-256

35. Haggstrom DA, Quale C, Smith-Bindman R (2005) Differences in the quality of breast cancer care among vulnerable populations. Cancer 104:2347-2358. https://doi.org/10.1002/cncr.21443

36. Richardson LC, Wang W, Hartzema AG, Wagner S (2007) The role of health-related quality of life in early discontinuation of chemotherapy for breast cancer. Breast J 13:581-587

37. Rosenzweig M, Connolly M (2016) Total dose of chemotherapy received in cohort of African American women with breast cancer. Oncol Nurs Forum 43:133

38. Rosenzweig M, Brufsky A, Rastogi P, Puhalla S, Simon J, Underwood S (2011) The attitudes, communication, treatment, and support intervention to reduce breast cancer treatment disparity. Oncol Nurs Forum 38:85-89. https://doi.org/10.1188/11.onf.85-89

39. Rosenzweig MQ, Wiehagen T, Brufsky A, Arnold R (2009) Challenges of illness in metastatic breast cancer: a low-income African American perspective. Palliat Support Care 7:143-152. https://doi.org/10.1017/S1478951509000194

40. von Friederichs-Fitzwater MM, Denyse RT (2012) The unmet needs of African American women with breast cancer. Adv Breast Cancer Res 2012:1-6

41. Yoon J, Malin JL, Tisnado DM, Tao ML, Adams JL, Timmer MJ, Ganz PA, Kahn KL (2008) Symptom management after breast cancer treatment: is it influenced by patient characteristics? Breast Cancer Res Treat 108:69-77. https://doi.org/10.1007/ s10549-007-9580-1
42. Inwald E, Ortmann O, Koller M, Zeman F, Hofstädter F, Evert M, Brockhoff G, Klinkhammer-Schalke M (2017) Screening-relevant age threshold of 70 years and older is a stronger determinant for the choice of adjuvant treatment in breast cancer patients than tumor biology. Breast Cancer Res Treat 163:119-130. https:// doi.org/10.1007/s10549-017-4151-6

43. Owusu C, Lash TL, Silliman RA (2007) Effect of undertreatment on the disparity in age-related breast cancer-specific survival among older women. Breast Cancer Res Treat 102:227-236. https://doi.org/10.1007/s10549-006-9321-x

44. Wheeler SB, Spencer JC, Pinheiro LC, Carey LA, Olshan AF, Reeder-Hayes KE (2018) Financial impact of breast cancer in black versus white women. J Clin Oncol 36:1695-1701. https:// doi.org/10.1200/JCO.2017.77.6310

45. Prigozin A, Uziely B, Musgrave CF (2010) The relationship between symptom severity and symptom interference, education, age, marital status, and type of chemotherapy treatment in Israeli women with early-stage breast cancer. Oncol Nurs Forum 37: E411-E418

46. Smith K, Wray L, Klein-Cabral M, Schuchter L, Fox K, Glick J, DeMichele A (2005) Ethnic disparities in adjuvant chemotherapy for breast cancer are not caused by excess toxicity in black patients. Clin Breast Cancer 6(3):260-266; discussion 267-269. https://doi.org/10.3816/CBC.2005.n.029

47. Fedewa SA, Ward EM, Stewart AK, Edge SB (2010) Delays in adjuvant chemotherapy treatment among patients with breast cancer are more likely in African American and Hispanic populations: a national cohort study 2004-2006. J Clin Oncol 28:4135-4141. https://doi.org/10.1200/JCO.2009.27.2427

48. Check DK, Chawla N, Kwan ML, Pinheiro L, Roh JM, Ergas IJ, Stewart AL, Kolevska T, Ambrosone C, Kushi LH (2018) Understanding racial/ethnic differences in breast cancer-related physical well-being: the role of patient-provider interactions. Breast Cancer Res Treat 170:593-603. https://doi.org/10.1007/ s10549-018-4776-0

49. Simon NB, Danso MA, Alberico TA, Basch E, Bennett AV (2017) The prevalence and pattern of chemotherapy-induced peripheral neuropathy among women with breast cancer receiving care in a large community oncology practice. Qual Life Res 26:2763-2772. https://doi.org/10.1007/s11136-017-1635-0

50. Bandos H, Melnikow J, Rivera DR, Swain SM, Sturtz K, Fehrenbacher L, Wade JL 3rd et al (2018) Long-term peripheral neuropathy in breast cancer patients treated with adjuvant chemotherapy: NRG Oncology/NSABP B-30. J Natl Cancer Inst 110:1

51. Gnerlich JL, Deshpande AD, Jeffe DB, Sweet A, White N, Margenthaler JA (2009) Elevated breast cancer mortality in women younger than age 40 years compared with older women is attributed to poorer survival in early-stage disease. J Am Coll Surg 208:341347. https://doi.org/10.1016/j.jamcollsurg.2008.12.001

52. Gaston-Johansson F, Watkins CC, Kanu IK, Whitehouse E, Sarenmalm EK, Brovall M, Kozachik SL (2015) The effects of symptoms on quality of life during chemotherapy in AfricanAmerican women with breast cancer. J Natl Black Nurses Assoc : JNBNA 26:7-16

53. Schneider BP, Li L, Radovich M, Shen F, Miller KD, Flockhart DA, Jiang G, Vance G, Gardner L, Vatta M, Bai S, Lai D, Koller D, Zhao F, O’Neill A, Smith ML, Railey E, White C, Partridge A, Sparano J, Davidson NE, Foroud T, Sledge GW (2015) Genomewide association studies for taxane-induced peripheral neuropathy in ECOG-5103 and ECOG-1199. Clin Cancer Res 21:5082-5091. https://doi.org/10.1158/1078-0432.Ccr-15-0586.

54. Miaskowski C, Cooper BA, Melisko M, Chen LM, Mastick J, West C, Paul SM, Dunn LB, Schmidt BL, Hammer M, Cartwright F, Wright F, Langford DJ, Lee K, Aouizerat BE (2014) Disease and treatment characteristics do not predict symptom occurrence profiles in oncology outpatients receiving 
chemotherapy. Cancer 120:2371-2378. https://doi.org/10.1002/ cncr.28699

55. Leach CR, Weaver KE, Aziz NM, Alfano CM, Bellizzi KM, Kent EE, Forsythe LP, Rowland JH (2015) The complex health profile of long-term cancer survivors: prevalence and predictors of comorbid conditions. J Cancer Surviv 9(2):239-251. https://doi. org/10.1007/s11764-014-0403-1

56. Braithwaite D, Tammemagi CM, Moore DH, Ozanne EM, Hiatt RA, Belkora J, West DW, Satariano WA, Liebman M, Esserman L (2009) Hypertension is an independent predictor of survival disparity between African-American and white breast cancer patients. Int J Cancer 124:1213-1219. https://doi.org/10.1002/ijc. 24054

57. Klepin HD, Pitcher BN, Ballman KV, Kornblith AB, Hurria A, Winer EP, Hudis C, Cohen HJ, Muss HB, Kimmick GG (2014) Comorbidity, chemotherapy toxicity, and outcomes among older women receiving adjuvant chemotherapy for breast cancer on a clinical trial: CALGB 49907 and CALGB 361004 (Alliance). J Oncol Pract 10:e285-e292. https://doi.org/10.1200/JOP.2014. 001388

58. Gatti ME, Jacobson KL, Gazmararian JA, Schmotzer B, Kripalani S (2009) Relationships between beliefs about medications and adherence. Am J Health Syst Pharm 66:657-664. https://doi.org/ 10.2146/ajhp080064

59. Sutton AL, He J, Edmonds MC, Sheppard VB (2018) Medical mistrust in black breast cancer patients: acknowledging the roles of the trustor and the trustee. J Cancer Educ 34:1-8. https://doi. org/10.1007/s13187-018-1347-3

60. Tucker CM, Moradi B, Wall W, Nghiem K (2014) Roles of perceived provider cultural sensitivity and health care justice in African American/Black patients' satisfaction with provider. J Clin Psychol Med Settings 21:282-290. https://doi.org/10.1007/ s10880-014-9397-0

61. Schneider BP, Lai D, Shen F, Jiang G, Radovich M, Li L, Gardner L, Miller KD, O’Neill A, Sparano JA, Xue G, Foroud T, Sledge GW Jr (2016) Charcot-Marie-Tooth gene, SBF2, associated with taxane-induced peripheral neuropathy in African Americans. Oncotarget 7:82244-82253. https://doi.org/10.18632/oncotarget. 12545

62. Hertz DL, Roy S, Motsinger-Reif AA, Drobish A, Clark LS, McLeod HL, Carey LA, Dees EC (2013) CYP2C8*3 increases risk of neuropathy in breast cancer patients treated with paclitaxel. Ann Oncol 24:1472-1478. https://doi.org/10.1093/annonc/ mdt018

63. Baldwin RM, Owzar K, Zembutsu H, Chhibber A, Kubo M, Jiang C, Watson D, Eclov RJ, Mefford J, McLeod HL, Friedman PN, Hudis CA, Winer EP, Jorgenson EM, Witte JS, Shulman LN, Nakamura Y, Ratain MJ, Kroetz DL (2012) A genome-wide association study identifies novel loci for paclitaxel-induced sensory peripheral neuropathy in CALGB 40101. Clin Cancer Res 18: 5099-5109

64. Abraham JE, Guo Q, Dorling L, Tyrer J, Ingle S, Hardy R, Vallier AL, Hiller L, Burns R, Jones L, Bowden SJ, Dunn JA, Poole CJ, Caldas C, Pharoah PPD, Earl HM (2014) Replication of genetic polymorphisms reported to be associated with taxane-related sensory neuropathy in patients with early breast cancer treated with paclitaxel. Clin Cancer Res 20:2466-2475

65. Apellaniz-Ruiz M, Sanchez-Barroso L, Gutierrez-Gutierrez G, Sereno M, Garcia-Donas J, Avall-Lundqvist E, Green H, Brosen K, Bergmann TK, Rodriguez-Antona C (2015) Replication of genetic polymorphisms reported to be associated with taxanerelated sensory neuropathy in patients with early breast cancer treated with paclitaxel-letter.erratum appears in. Clin Cancer Res 21(18):4244 Clin Cancer Res 21:3092-3093.
66. Boso V, M J Herrero A, Santaballa L, Palomar JE, Megias H, de la Cueva L, Rojas et al (2014) SNPs and taxane toxicity in breast cancer patients. Pharmacogenomics 15:1845-1858

67. Smith AK, Conneely KN, Pace TWW, Mister D, Felger JC, Kilaru V, Akel MJ, Vertino PM, Miller AH, Torres MA (2014) Epigenetic changes associated with inflammation in breast cancer patients treated with chemotherapy. Brain Behav Immun 38:227-236. https://doi.org/10.1016/j.bbi.2014.02.010

68. Bigby JA, Holmes MD (2005) Disparities across the breast cancer continuum. Cancer Causes Control 16(1):35-44. https://doi.org/ 10.1007/s10552-004-1263-1

69. Bradley CJ, Given CW, Roberts C (2002) Race, socioeconomic status, and breast cancer treatment and survival. JNCI: J Natl Cancer Inst 94(7):490-496. https://doi.org/10.1093/jnci/94.7.490

70. Bustami RT, Shulkin DB, O’Donnell N, Whitman ED (2014) Variations in time to receiving first surgical treatment for breast cancer as a function of racial/ethnic background: a cohort study. JRSM open 5(7):2042533313515863-2042533313515863. https://doi.org/10.1177/2042533313515863

71. Daly B, Olopade OI (2015) A perfect storm: how tumor biology, genomics, and health care delivery patterns collide to create a racial survival disparity in breast cancer and proposed interventions for change. CA Cancer J Clin 65:221-238. https://doi.org/ 10.3322/caac. 21271

72. Lund MJ, Brawley OP, Ward KC, Young JL, Gabram SS, Eley JW (2008) Parity and disparity in first course treatment of invasive breast cancer. Breast Cancer Res Treat 109(3):545-557. https:// doi.org/10.1007/s10549-007-9675-8

73. Popescu I, Schrag D, Ang A, Wong M (2016) Racial/ethnic and socioeconomic differences in colorectal and breast cancer treatment quality: the role of physician-level variations in care. Med Care 54(8):780-788. https://doi.org/10.1097/mlr. 0000000000000561

74. Wheeler SB, Reeder-Hayes KE, Carey LA (2013) Disparities in breast cancer treatment and outcomes: biological, social, and health system determinants and opportunities for research. Oncologist 18(9):986-993. https://doi.org/10.1634/theoncologist. 2013-0243

75. Gwyn K, Bondy ML, Cohen DS, Lund MJ, Liff JM, Flagg EW, Brinton LA, Eley JW, Coates RJ (2004) Racial differences in diagnosis, treatment, and clinical delays in a population-based study of patients with newly diagnosed breast carcinoma. Cancer 100(8):1595-1604. https://doi.org/10.1002/cncr.20169

76. Chen L, Li CI (2015) Racial disparities in breast cancer diagnosis and treatment by hormone receptor and HER2 status. Cancer Epidemiol Biomark Prev 24(11):1666-1672. https://doi.org/10. 1158/1055-9965.Epi-15-0293

77. Bickell NA, Wang JJ, Oluwole S, Schrag D, Godfrey H, Hiotis K, Mendez J, Guth AA (2006) Missed opportunities: racial disparities in adjuvant breast cancer treatment. J Clin Oncol 24:1357-1362. https://doi.org/10.1200/jco.2005.04.5799

78. Chavez-MacGregor M, Clarke CA, Lichtensztajn DY, Giordano SH (2016) Delayed initiation of adjuvant chemotherapy among patients with breast cancer. JAMA Oncology 2:322-329. https:// doi.org/10.1001/jamaoncol.2015.3856

79. McFarland DC, Shaffer KM, Tiersten A, Holland J (2018) Prevalence of physical problems detected by the distress thermometer and problem list in patients with breast cancer. Psychooncology 27(5):1394-1403. https://doi.org/10.1002/pon.4631

80. Miaskowski C, Cooper B, Paul SM, West C, Langford D, Levine JD, Abrams G, Hamolsky D, Dunn L, Dodd M, Neuhaus J, Baggott C, Dhruva A, Schmidt B, Cataldo J, Merriman J, Aouizerat BE (2012) Identification of patient subgroups and risk factors for persistent breast pain following breast cancer surgery. $\mathrm{J}$ Pain : official journal of the American Pain Society 13(12):11721187. https://doi.org/10.1016/j.jpain.2012.09.013 
81. Nurgalieva Z, Liu C-C, Du XL (2011) Chemotherapy use and risk of bone marrow suppression in a large population-based cohort of older women with breast and ovarian cancer. Med Oncol 28:716725. https://doi.org/10.1007/s12032-010-9512-5

82. Janelsins MC, Heckler CE, Peppone LJ, Kamen C, Mustian KM, Mohile SG, Magnuson A, Kleckner IR, Guido JJ, Young KL, Conlin AK, Weiselberg LR, Mitchell JW, Ambrosone CA, Ahles TA, Morrow GR (2017) Cognitive complaints in survivors of breast cancer after chemotherapy compared with age-matched controls: an analysis from a nationwide, multicenter, prospective longitudinal study. J Clin Oncol : official journal of the American Society of Clinical Oncology 35(5):506-514. https://doi.org/10. 1200/JCO.2016.68.5826

83. Geronimus AT, Hicken M, Keene D, Bound J (2006) "Weathering" and age patterns of allostatic load scores among blacks and whites in the United States. Am J Public Health 96(5):826-833. https://doi.org/10.2105/ajph.2004.060749

84. Geronimus AT, Hicken MT, Pearson JA, Seashols SJ, Brown KL, Cruz TD (2010) Do US black women experience stress-related accelerated biological aging?: a novel theory and first population-based test of black-white differences in telomere length. Hum Nat 21(1):19-38. https://doi.org/10.1007/s12110010-9078-0

85. Pearson JA, Geronimus AT (2018) A practical guide to biological primary data collection in an impoverished urban setting: illuminating structural and social influences on population health inequity. SAGE Research Methods Cases, London

86. Tammemagi CM, Nerenz D, Neslund-Dudas C, Feldkamp C, Nathanson D (2005) Comorbidity and survival disparities among black and white patients with breast cancer. JAMA 294(14):17651772. https://doi.org/10.1001/jama.294.14.1765

87. Gallups SF, Connolly MC, Bender CM, Rosenzweig MQ (2018) Predictors of adherence and treatment delays among African American women recommended to receive breast cancer chemotherapy. Womens Health Issues 28(6):553-558. https://doi.org/10. 1016/j.whi.2018.08.001

88. Edwards MJ, Campbell ID, Lawrenson RA, Kuper-Hommel MJ (2017) Influence of comorbidity on chemotherapy use for early breast cancer: systematic review and meta-analysis. Breast Cancer Res Treat 165(1):17-39. https://doi.org/10.1007/s10549-0174295-4

89. Gaston-Johansson F, Haisfield-Wolfe ME, Reddick B, Goldstein N, Lawal TA (2013) The relationships among coping strategies, religious coping, and spirituality in African American women with breast cancer receiving chemotherapy. Oncol Nurs Forum 40: $120-131$

90. Han W, Lee S (2016) Racial/ethnic variation in health care satisfaction: the role of acculturation. Soc Work Health Care 55:694 710. https://doi.org/10.1080/00981389.2016.1191580

91. Robertson-Jones TA, Tissue MM, Connolly M, Gallups SF, Bender CM, Rosenzweig MQ (2018) Exploring racial differences in patient centeredness of care (PCC) during breast cancer (BC) chemotherapy clinical visits. J Racial Ethn Health Disparities 6: 94-100. https://doi.org/10.1007/s40615-018-0503-0

92. Jabir RS, Naidu R, Annuar MABA, Ho GF, Munisamy M, Stanslas J (2012) Pharmacogenetics of taxanes: impact of gene polymorphisms of drug transporters on pharmacokinetics and toxicity. Pharmacogenomics 13:1979-1988. https://doi.org/10. 2217/pgs.12.165

93. Arbitrio M, Martino MTD, Scionti F, Barbieri V, Pensabene L, Tagliaferri P (2018) Pharmacogenomic profiling of ADME gene variants: current challenges and validation perspectives. High Throughput 7(4). https://doi.org/10.3390/ht7040040

94. Hovelson DH, Xue Z, Zawistowski M, Ehm MG, Harris EC, Stocker SL, Gross AS, Jang IJ, Ieiri I, Lee JE, Cardon LR, Chissoe SL, Abecasis G, Nelson MR (2017) Characterization of ADME gene variation in 21 populations by exome sequencing. Pharmacogenet Genomics 27(3):89-100. https://doi.org/10.1097/ fpc.0000000000000260.

95. Jack J, Havener TM, McLeod HL, Motsinger-Reif AA, Foster M (2015) Evaluating the role of admixture in cancer therapy via in vitro drug response and multivariate genome-wide associations. Pharmacogenomics 16:1451-1463. https://doi.org/10.2217/PGS. 15.85

96. Li J, Lao X, Zhang C, Tian L, Lu D, Xu S (2014) Increased genetic diversity of ADME genes in African Americans compared with their putative ancestral source populations and implications for pharmacogenomics. BMC Genet 15:52. https://doi.org/10.1186/ 1471-2156-15-52

97. Lynch T, Price A (2007) The effect of cytochrome P450 metabolism on drug response, interactions, and adverse effects. Am Fam Physician 76:391-396

98. Landry LG, Ali N, Williams DR, Rehm HL, Bonham VL (2018) Lack of diversity in genomic databases is a barrier to translating precision medicine research into practice. Health Aff (Millwood) 37:780-785. https://doi.org/10.1377/hlthaff.2017.1595

99. Morales J, Welter D, Emily H, Bowler MC, Harris LW, McMahon AC, Hall P et al (2018) A standardized framework for representation of ancestry data in genomics studies, with application to the NHGRI-EBI GWAS Catalog. Genome Biol 19:1-10. https://doi. org/10.1186/s13059-018-1396-2

100. Roseland ME, Schwartz K, Ruterbusch JJ, Lamerato L, Krajenta R, Booza J, Simon MS (2017) Influence of clinical, societal, and treatment variables on racial differences in $\mathrm{ER}-/ \mathrm{PR}$ - breast cancer survival. Breast Cancer Res Treat 165:163-168. https://doi.org/10. 1007/s10549-017-4300-y

101. Barsevick AM, Leader A, Bradley PK, Avery T, Dean LT, DiCarlo M, Hegarty SE (2016) Post-treatment problems of African American breast cancer survivors. Support Care Cancer 24(12): 4979-4986. https://doi.org/10.1007/s00520-016-3359-z

102. Healthy People 2020. U.S. Department of Health and Human Services, Office of Disease Prevention and Health Promotion. https://www.healthypeople.gov/2020/topics-objectives/topic/ social-determinants-of-health. Accessed 3/19/2019.

103. Zannas AS, Arloth J, Carrillo-Roa T, Iurato S, Roh S, Ressler KJ, Nemeroff CB et al (2015) Lifetime stress accelerates epigenetic aging in an urban, African American cohort: relevance of glucocorticoid signaling. Genome Biol 16:266. https://doi.org/10.1186/ s13059-015-0828-5.

Publisher's Note Springer Nature remains neutral with regard to jurisdictional claims in published maps and institutional affiliations. 